\title{
Health production for elderly persons and their
} caregivers

\begin{abstract}
A descriptive, qualitative study was undertaken to address nursing actions to support the family caregivers of dependent elderly persons in dealing with care needs, aimed at ensuring a better quality of life for both caregivers and the elderly. The setting was the Geriatric Outpatient Clinic of a Public University Hospital in Rio de Janeiro, Brazil. A research-action methodology was employed family caregivers as co-researchers. The present work represents a strategy for institutional support, strengthening health services and improving support for family caregivers.
\end{abstract}

Keywords: nursing, elderly person, caregiver
Volume 4 Issue 4 - 2019

\author{
Barbara Martins Corrêa da Silva,' \\ Célia Pereira Caldasb, ${ }^{2}$ Ivone Renor da \\ SilvaConceiçãoc, ${ }^{3}$ Claudia Feio da Maia \\ $\operatorname{Limad}^{4}$ \\ 'Outpacient clinic, University hospital Clementino Fraga Filho, \\ Brazil \\ ${ }^{2}$ Faculty of Nursing. Department of Public Health Nursing. Brazil \\ ${ }^{3}$ The Elderly Care Center, Brazil \\ ${ }^{4}$ Area of Health Practices, The Federal University Santo Antônio \\ de Jesus, Brazil
}

Correspondence: Barbara Martins Corrêa da Silva, Faculdade de Enfermagem da Universidade do Estado do Rio de Janeiro, Boulevard 28 de setembro, I57,Vila Isabel, Rio de Janeiro- RJ, Brazil,Tel (21)2868-8326, Email barbaramartins.enf@gmail.com

Received: July 08, 2019 | Published: July II, 2019

\section{Introduction}

This study considers nursing strategies to support family caregivers of dependent elderly persons in daily coping with care needs. The intention is to support caregivers to guarantee the possibility of a future that ensures quality of life for themselves and for the elderly, which represents a long-term challenge.

The intensive provision of care can negatively affect the health of caregivers. ${ }^{1}$ In some families, the caregiver lives in a solitary environment as other family members choose to keep their distance. ${ }^{2}$

As dependency increases, the caregiver needs to address care needs related to daily living activities, including materials for consumption and equipment suitable for procedures of care, special feeding, and medication. Financial limitations can subsequently become a stressgenerating factor for the caregiver. ${ }^{3}$

The situation becomes more serious when the degree of dependency of the elderly person increases, as this generates greater expense in the care process. When the purchasing power of the caregivers is limited, this can compromise the care given to the elderly person. ${ }^{4}$

Studies also show that a low level of schooling can generate great emotional tension and stress, as well as a lack of access to services and social support, generating an unsuitable environment for care, and harm to both the elderly person and the family caregiver. ${ }^{5}$

Considering all these factors, a study was developed with family caregivers. Therefore, the aim of the present study was to develop a nursing caring model constructed in partnership with nurses and caregivers of the elderly using the action research methodology.

This study is relevant for geriatric nursing. Family care is part of our life process as it is impossible to predict whether a family member will become dependent or not. In this sense, nursing must take ownership of issues related to family care, always considering that they are dynamic, historical and social processes. ${ }^{2}$

\section{Methods}

\section{Design}

The objective was to develop and construct a caring model by using the Action Research (AR) methodology with nurses and family caregivers being the co-researchers. AR is a viable alternative to reapproximating academic research to society, due to its commitment to intervention in reality (Menelau et al., 2015).

The study design included four steps:1) meeting of nurses to plan the workshops; 2) workshops with caregivers; 3) nurses meeting to discuss the results of the content analysis of the workshops and to elaborate the action plan; 4) the researchers elaborated the caring model.

\section{Setting and participants}

The setting was the geriatrics outpatient clinic of a university hospital, forming part of the public health service, located in Rio de Janeiro, Brazil. Meetings were held with the management committee of the outpatient clinic to discuss the spatial challenges and options related to the carrying out of the research. This information was fundamental for the planning of the study design. From these meetings emerged the idea of holding workshops regarding "caring for those who care".

The inclusion criteria of the study participants were agreed with the group of nurses from the outpatient clinic, and the inclusion criteria for the caregiver group were defined as: have been a family caregiver of an elderly person for at least six months; age $\geq 18$ years; and voluntary agreement to participate in the study. The present study was submitted to the Research Ethics Committee of HUPE and approved under protocol number CAAE 4449901520005282, on July 23, 2015, based on its compliance with the directives and guidelines on research involving human beings established by Resolution $\mathrm{N}^{\circ} 466$ of the National Health Council, dated December 12, 2012. ${ }^{\text {. }}$ 
The testimonies and collective production of the co-researchers were recorded through digital recording, the creation of posters, photography, a field diary and discovery cards. Identification was by letters and numbers, with the letters $\mathrm{CP}$ corresponding to the caregiver participants and $\mathrm{RN}$ to the researcher-nurses. The enumeration refers to the order of the speeches (ex: CP1 and RN1). The content analysis of Bardin ${ }^{6}$, a research technique aimed at the objective, systematic and quantitative description of the manifest content of communication was used to analyze the content of the speeches and written production of the co-researchers during the workshops.

\section{Results}

\section{Characterization of study participants}

Of the 12 caregivers, three were spouses, five were sons or daughters and four were sons in law or daughters in law. The age group varied from 59 to 84 years, and eight caregivers were women and four were men. With respect to marital status, seven caregivers were married, two were widowed, two were unmarried and one was divorced. Eight caregivers lived with the elderly person. In relation to profession, three worked in accounting, two were housewives and three were teachers. There was also one nursing assistant, one party organizer, one commercial manager and one administrator. Seven had completed higher education, two had finished secondary education and two had a primary level education.

Three caregivers cared for an elderly person alone, seven shared care responsibilities with other people in the family (son in law or daughter in law, son or daughter, husband or wife), and two shared care responsibilities with a hired caregiver.

Family income varied from $\$ 476$ to $\$ 3,338$ (dollars), although two people did not provide information about their income. Ten caregivers were retired, one was still working, and one had never worked.

In terms of health problems, five people had SAH; 3 had diabetes mellitus; one had hypothyroidism, two had asthma and one described having no health problems. Ten people had attended the outpatient clinic of the NAI for more than two years. The time the caregivers had spent caring for an elderly person varied from two to ten years. Five people cared for the elderly person 24 hours a day.

The categories found in the group of caregivers were: 1) difficulties and 2) future perspectives, while the nurses group identified: 1) contradictions and 2) the proposals of work. These categories will be presented and discussed below.

\section{Analysis of meetings with caregivers}

When analyzing the five workshops transcripts two categories were identified; difficulties and future perspective?

Regarding difficulties, the first category identified, themes emerged relating to the obstacles of caring for dependent elderly persons, family conflicts, financial problems and difficulties in accessing the basic health care service. One speech unit described the difficulty of dividing time between caring for oneself and caring for another:

"We worry so much about the other person that we neglect ourselves. I've heard of a case where someone providing care passed away before the person being cared for" cp 3.

Studies show that the duration of the care provided for the elderly person, the level of dependency and the level of intimacy between the caregiver and the elderly person affect caregivers. Psychological support is therefore required if the caregiver is not to fall $i 11 .^{8}$ In addition, social class is a key category for the study of the social determination of the health-disease process, as conditions of class affect material factors, life experiences and the capacity for collective action. ${ }^{9}$

In this sense, professionals can offer alternatives for the control of expenses without sacrificing the quality of care. These guidelines help in the reorganization of care and enhance adherence to treatment.

The second category that emerged from the workshops with caregivers deals with their future perspectives.

"If you want your mother to be treated well. The hospital .... I've already decided that I'm going there, I have a nice, big house, I'll rent out my house and stay there" cp27.

The future perspectives category reveals how caregivers imagine themselves in the years to come, their anxieties and their ideal of life. In this speech, the caregiver is projecting a future where they are cared for in a long-term institution and not in the home context, because they do not see their children as being willing to reproduce the care they provided to their parents. It is important that a family talks about the planning of care throughout life, so that when an elderly person becomes dependent, it has been previously agreed who will be the legal representative or caregiver, or whether the person prefers to be institutionalized. ${ }^{10}$

When caregivers talked about their history with the elderly persons in the workshops, they often revealed a history of conflict, hurt and forgiveness. On this occasion, they were reflective, and some even cried. It was observed that the dependence of care recalls situations experienced in the past, with care being a portal to the possibility of new relations between the elderly person and the caregiver.

Therefore, life history and social relationships should be considered, as when evaluating family functionality it is important to understand not only how the support network functions, but also how this network was constructed.

The workshops noted the need for caregivers to have professional support to help mobilize internal and external resources to provide better care. This can be identified in the following speech unit:

I hope to improve more, to have patience, to not despair any more, to not stop going to lectures" cp11

\section{Final considerations}

Through this study, it was possible to understand that the most frequently occurring contradictions in the discourse of the coinvestigators were: the dilemma regarding self-care and the care of others, the confrontation between the caregiver and the elderly person, the conflict between the main caregiver and other members of the family, and the contradiction between public policies and reality.

The workshops "caring for those who care" was a health promotion activity strategy and when the analyzed content of the workshops was presented to the nurses, they were able to compare it with their professional experience in the outpatient clinic and produce a plan of action. Finally, strategies were developed to improve care for these families, such as the continuation of the workshops and the extension of the caregiver group to include more ludic activities, improvement of the reception process, the return of care and interconsultations. 
The present work represents a strategy for institutional support, strengthening health services and improving support for family caregivers.

\section{Acknowledgments}

None.

\section{Conflict of interests}

Authors declare that there is no conflict of interest.

\section{References}

1. Oshio T. How is an informal caregiver's psychological distress associated with prolonged caregiving? Evidence from a six-wave panel survey in Japan. Qual Life Res. 24(12):2907-2915.

2. Araújo JS. The obligation to des (caring): social representations about caring for the sequelae of stroke by their caregivers. Rev Min Enferm. 2012;16(1):98-105.

3. Uesugui, HM, Fagundes DS, Pinho DLM. Profile and degree of dependency of the elderly and overload of their caregivers.. Acta paul enferm. 2011;24(5):689-694.
4. Nardi EFR, Sawada, NO, Santos JLF. Association between the functional incapacity of the elderly and the overload of the family caregiver. Rev Latino-Am Enfermagem. 2013;21(5):1-8.

5. Oliveira DC, D'elboux MJ. National studies on family caregivers of the elderly: integrative review. Rev bras enferm..2012. 65(5):829-838.

6. Bardin L. Content analysis. Lisbon . 2011:70.

7. National health council. Resolution 466 of December 12, 2012, Approves the guidelines and norms regulating research involving human beings. Brazil; 2013.

8. Arican B, Guney M, Akbal N. et al. Determining depression level of caregivers providing home healthcare services. North Clin Istanb. 2016;3(2):118-123.

9. Barata RB. Health in large metropolises and socially vulnerable populations. Revista USP. 2015;107:27-42.

10. Michael N, O'Callaghan C, Sayers E. Managing 'shades of grey': a focus group study exploring community-dwellers' views on advance care planning in older people. BMC Palliat Care. 2017;16(1):2. 